\title{
Developing brand equity through consumers: A study of pharmaceutical industry
}

\author{
Ashok Panigrahi ${ }^{*}$, Vijay Joshi \\ ${ }^{\mathbf{1}}$ Associate Professor, ${ }^{\mathbf{2}}$ Assistant Professor, ${ }^{1}$ NMIMS University, Shirpur, Maharashtra, India, ${ }^{2}$ Dr. Ambedkar Institute of Management \\ Studies \& Research, (DAIMSR) Nagpur, RTM Nagpur University, Nagpur, Maharashtra, India \\ *Corresponding Author: Ashok Panigrahi \\ Email: ashok.panigrahi@nmims.edu
}

\begin{abstract}
Brand equity development has been a recent trend in the pharmaceutical industry and is seeing a rapid growth in this segment of the market. Brand equity is the most influential factor among various competitors and thus affects the industry in all sense. In the early days, the pharmaceutical industry did not take much note to the branding and to increase the market share. It has become essential to increase the brand equity among the consumers. The brand equity not only helps in attracting the consumers but also the people who are unaware about the brands that are existing. These methods are not only useful in the means to earn the brand equity but also help in the company to retain in the market with a good position among the competitors. These are also the key factors that affect the growth of the industries, not only the sales force is attributed to build the brand, but also the appropriate knowledge has to be provided to increase the standards of the brand. There are also chances that arises that the generic drugs are acquiring and affecting the branding of the drugs. Due to the rise in the generic market, the company must also make advances in their strategies. This includes the lowering of the prices of the drugs as well as the competition from these products.

The impact of the brands in these days can be widely seen with the use of the various consumer-oriented strategies deployed by the Pharma companies in the development of their brands and in promoting their products. Apart from using, various advertisements to increase awareness about the products needs of the consumers are driving the 'brand equity'. This will not only enhance the product marketing standards but also may establish a distinct mark as and when compared with other competitors.
\end{abstract}

Keywords: Brand equity, Pharmaceutical organizations, Brand loyalty, Brand strategy, Brand awareness, Generics.

\section{Introduction}

Pharmaceutical companies are highly dependent on data and facts to sell and market their product. New drugs were easy to differentiate from their competitors and both physicians and patients brought easily up to their advantages in terms of efficacy and/or side effects.

However, not anymore....

Since the landscape of the industry is changing, competition intensifies, pipelines are drying up and new drugs do not usually bring breakthroughs in treatment, pharmaceutical companies seek for a new concept to differentiate their products and maximize their lifetime value. Hence branding appeared as an appealing path to follow. It has been proved effective in consumer goods markets so why not in pharmaceuticals?

It seems extraordinary that one of the world's largest consumer good markets - pharmaceuticals - should have flourished with little help from brands. It is the brand, which provides the sole means of differentiation, branding ultimately will be the only unique differentiator between companies. Brand equity is now a key asset."

The pharmaceutical industry has come late to branding. During the 1980s and 1990s, the pharmaceutical industry enjoyed success over an extended period, achieving doubledigit growth consistently. The success of the industry depended on strong $\mathrm{R} \& \mathrm{D}$, use of patent, and a powerful sales force. However, with growth in the industry slowing down, firms have been searching for new ways to maintain their brand positions (Schuiling and Moss, 2004a). Consequently, pharmaceutical companies have had to embrace marketing and branding strategies largely than they have been in the past (Blackett, 2005). For decades, pharmaceutical companies' brands strategy was to discover a brand that was needed, introduce it to Doctors via a sales representative, and watch the prescriptions are filled. With several factors causing change in the pharmaceutical industry in the way in which medications are marketed, it has become crucially important for these companies to brand their products. This is critical in view of the fact that more and more drugs are progressively sold over the counter (Kapoor and Epstein, 2004). It is evident that the competitive environment is becoming more intense in the pharmaceutical industry. As a result, (Schuiling and Moss, 2004a) consider that branding can represent a new competitive lever that can project a firm in the marketplace. With retail brands now, competing with generic drugs (including private labels), alternative and complementary treatments, and pharmaceutical companies cannot overlook or downplay the immense power branding.

\section{What is Branding?}

Branding is an effective method through which a consumer can distinguish between various goods through various brand. According to American Marketing Association, a brand is a name, term, symbol, design or a combination of them intended to identify the goods and services of one seller or a group of sellers and to differentiate from those of competition. (Keller, 2005)

According to (Schuiling and Moss, 2004b), a brand is a name that will register the product in the consumer's mind as a set of tangible, that is rational, and intangible, that is irrational, benefits. A product on its own delivers tangible benefits, whereas a brand offers additional values that arc 
both the tangible and intangible benefits. For example, the Mercedes brand is registered in the mind of consumers as a brand offering a set of tangible benefits (solidity, reliability and of German quality) and intangible benefits (success, status) (Moss, 2004b). Kotler (as cited in Keller, 2005) defines a product as anything that can be offered to a market for use or consumption that might satisfy a need or want. It may be a physical good, service, retail store, person, organization, place or idea (Keller, 2005). Levitt (as cited in Keller, 2005) concurs and adds that a brand is a product, but one that adds other dimensions that differentiate it in some way from other products. Additionally, the sum total of consumers' perceptions and feelings about the product's attributes and how it performs, about the brand name and what it symbolizes, and about the company associated with the brand, are the elements that distinguish a brand from its unbranded counterpart (Keller, 2005). The ultimate goal of a brand is not just to be remembered, or differentiated from competitors, but also to be the only answer to what the audience needs (Malone, 2004).

There is imperative need to understand what customerbased brand equity is and to comprehend the steps of brand building. Customer-based brand equity is the differential effect that brand knowledge has on customer response to the marketing of that brand. When customers react more positively to a product and the way it is marketed when the brand is identified than when it is not, that brand has positive customer-based brand equity. Customer- based brand equity occurs when the consumer has a high-level knowledge of brand awareness and strong, favorable, unique associations with the brand (Keller, 2005).

\section{Brand Equity}

Brand equity is phrase used in the marketing industry. It broadly refers to the perceived worth of a brand in and of itself i.e. the social value of well-known brand name. Brand equity has four dimensions viz. brand awareness, perceived quality, brand associations, and brand loyalty. It may be said that each of these aspect provides value to an organization in numerous ways (Panchal et al., 2012). (Fig. 1)

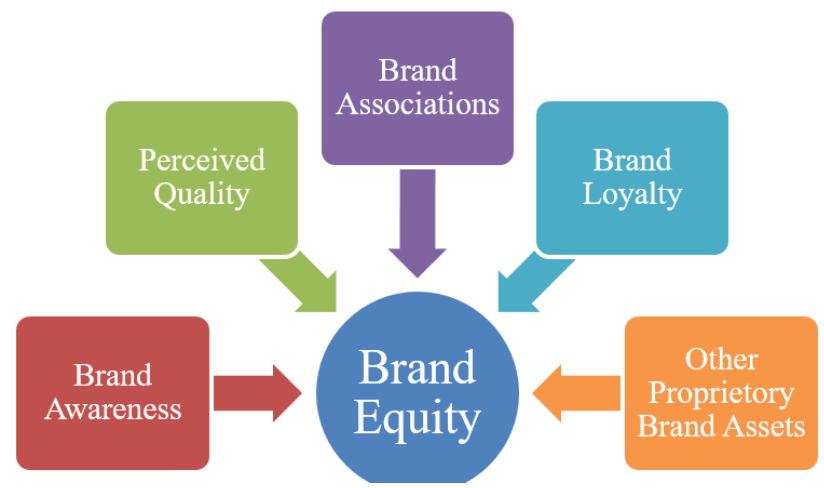

Fig. 1: Brand equity and its components

Brand equity is a set of brand asset and liabilities linked to a brand that includes brand loyalty, brand awareness, perceived quality and associations. The brand loyalty of the customer base is often the core of brand's equity. Building awareness is much easier over a longer time because learning works better with repetition and reinforcement. Perceived quality is the customer's perception of the overall quality or superiority of a product service with respect to its intended purpose, relative to alternatives. Much research has been done on whether or not branding plays a role in consumer purchases. In case of pharmaceutical industry in India, creating good enough brand awareness, loyalty and communicating compelling quality for good perceptions amongst numerous generic environments is a key challenge to increase brand equity (Panchal et al., 2012).

\section{Brand Equity related Perspectives}

Three perspectives of brand equity are as follows:

1. Financial

2. Brand Extensions

3. Consumer-based

\section{Financial}

Brand equity can be measured by determining the price premium that brand commands over a generic product. For example, if consumers are willing to pay $\$ 100$ more for branded camera over the same unbranded camera, this premium provides important information about the value of the brand. However, expenses such as promotional costs must be taken into account when using this method to measure brand equity.

\section{Brand extension}

A successful brand can be used as a platform to launch related products. The benefits of brand extension are the leveraging of existing brand awareness thus reducing advertising expenditures, and a lower risk from the perspective of the consumer. Furthermore, appropriate brand extensions can enhance the core brand. However, the value of brand extension is more difficult to quantify than are direct financial measures of brand equity.

\section{Consumer-based}

"The differential effect that brand knowledge has on consumer response to marketing of the brand" (Keller, 2005). A strong brand increases the consumer's attitude strength toward the product associated with the brand. Attitude strength is built by experience by the customer implies that trial samples are more effective than advertising in the early stages of building a strong brand. The consumer's awareness and associations lead to perceived quality, inferred attributes and eventually, brand loyalty.

\section{Measurement of Brand Equity}

Brand equity is measured in two ways either by internal measurement or by external measurement. Internal measurement ensures that employees are living the brand and delivering the experience from an organizational alignment perspective. External measurement is measuring to what degree customers and prospects are experiencing your brand in ways that will cause them to become more 
committed. Brand equity can be measured by the following types, they are aided unaided awareness of the company brand, including values, personality, and associations and messages. Other related aspects are customer brand loyalty and customer's willingness to pay price, whether the customer will like the product or not. These should be used in the internal and external measurement of the brand equity measurement. Apart from these the best method is to use the in depth phone aided method supported by larger sample of web based surveys to provide statistical legitimacy. Another method is to do a statistical survey by doing customer check by creating customer council and taking their opinions. This can be done by taking their customer ideas and views about it.

A report conducted by health branding agency Inter brand Health measures the value that brands alone provide pharmaceutical companies. Called Best Pharma Brands, the report is a ranking of the top 10 Pharma brands, quantifying the corporate brand's contribution to business performance in the biopharmaceutical industry.

According to the study, brand value is a single measure of the brand's contribution to business results. Brand valuations were determined by a financial analysis of the brand in business results, the influence a brand has on customer willingness to recommend and measured brand performance relative to the competition.

The study does not look at the strength of individual product brands. Rather, it is an assessment of the overall corporate brand as a drug manufacturer.

The Pharma brand with the highest value is Pfizer, with an estimated brand value just shy of $\$ 20$ billion. In second place is The Roche Group, with a brand value of approximately of $\$ 15.5$ billion, and they followed by five brands in spots three through seven with valuations in the $\$ 13$ billion range. Pfizer is not the top of market cap, but it is the top in role of brands. Other companies were lower in market cap, but because of the strength of their brand, they actually were higher in their brand rankings.

The fact that some labels are over performing relative to their market capitalization number could mean that cap has room to grow.

Another significant finding was that the role brand plays when influencing recommendations. When weighed against other factors, such as product efficacy and safety, product formulation, other product features and/or reimbursement, the role of brand was found to be the determining factor in a recommendation $11 \%$ of the time and it was observed that there was a significant $57 \%$ jump from 2013.

According to OBR Market Research Report: Competing for Image Leadership, image leadership in oncology is taking on increased importance as performance; customer satisfaction and loyalty become inextricably linked to customer experience. Being the leader in image creates a positive perception for those highly ranked companies and drives those behaviors that are critical to being successful in today's environment.

Using their proprietary MSImage ${ }^{\mathrm{TM}}$ methodology, they did the survey, on an annual basis, 465 oncologists and hematologists, 100 oncology practice managers and 100 oncology nurses to determine who are the image leaders, which attributes most differentiate companies (key drivers), and how companies can improve their image and performance.
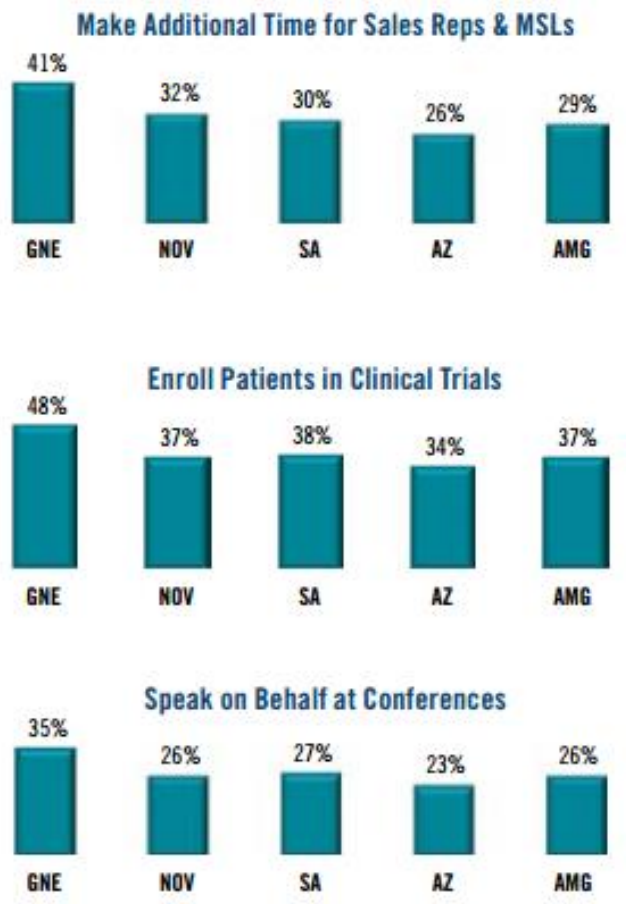

Fig. 2: Graphs from survey by OBR market research

The graph suggests (Fig. 2), image leadership helps companies connect to their customers in a world where relationships are more difficult and battlegrounds for share of voice reach beyond the traditional marketplace. As competition for stakeholder commitment intensifies, image leadership becomes a more tangible asset. Companies that become image leaders are able to drive "engagement" behaviors with their customers and truly derive the benefits of performance. The challenge to companies, however, is to identify these engagement behaviors (or customer touch points), measure performance against their competitors, and understand how performance leadership can have a positive impact on customers' experience. 
Table 1: Comparative table for select companies - survey by OBR market research

\begin{tabular}{|l|l|c|c|}
\hline Rank & Sales Force & Corporate Equity & Product / R\&D \\
\hline 1 & Genetech & Genetech & Genetech \\
\hline 2 & Novartis & Novartis & Novartis \\
\hline 3 & Sanofi-Aventis & Sanofi-Aventis & Sanofi-Aventis \\
\hline 4 & Astra Zenca & AstreZenca & Amgen \\
\hline 5 & Celgene & Amgen & AstraZeneca \\
\hline 6 & Eli Lilly/ImClone & Eli Lilly/ImClone & Celgene \\
\hline 7 & Amgen & Celgene & Glaxo-SmithKline \\
\hline 8 & Pfizer & Glaxo-SmithKline & Pfizer \\
\hline 9 & Glaxo-SmithKline & BMS & BMS \\
\hline 10 & BMS & Pfizer & \\
\hline
\end{tabular}

According to report, Genentech leads in all three dimensions (Fig. 3) and its lead is significant in the Product / R\&D area. Novartis remains second in 2009, and continues to challenge Genentech in the sales and corporate equity dimensions, followed closely by Sanofi-Aventis. AstraZeneca and Amgen have been trading 4th and 5th positions for the past few years but the most surprising performance has been by Celgene, which finished in 5th position among oncologists in sales force performance and is challenging Lilly, Amgen and AstraZeneca for overall 5th place among office-based oncologists.

\section{Ways of Enhancing Brand Equity}

Brand equity is measured in two ways either by internal measurement or by external measurement. Internal measurement ensures that employees are living the brand and delivering the experience from an organizational alignment perspective.

There are different ways to increase the brand equity in sales of Pharmaceutical industries.

Pharmaceutical Brands exist in the mind of the physicians and by asking the right questions target customers are segmented based on brand loyalty. This gives detailed information of brands key strengths and weaknesses in order to develop your marketing plans and explore options for increasing the share.

1. Brand awareness is a key for brand equity through which prescribers prescribes the drugs and if the physician is not aware of the brand the sales falls steeply.

2. Physicians may be aware of the brand but there are barriers like lack of performance, suitability of patients or high prices, which give other brand an upper hand so strategies are developed to overcome these barriers.

3. Once the potential barrier is overcome now offer the advantage over your competitor to attract the loyal prescribers. This is important because more the loyal prescribers more is the growth of the market share and less is the change in the market.eg. New launches price cutting etc.

Some of the broad drivers of loyalty are fame or popularity, rational benefit, emotional connections, innovation, price / value and differentiation. Popularity is the key driver of loyalty for pharmaceutical brand. Emotional connection is the next key driver, which is followed by rational benefit. Popularity and emotional connection are the important in therapy area of generic.

As mentioned by Trevor Acreman, there are different to increase sales through stronger brand equity. In this context, popularity and emotional association are the aspects that are responsible for establishment of brand loyalty (Fig. 4).

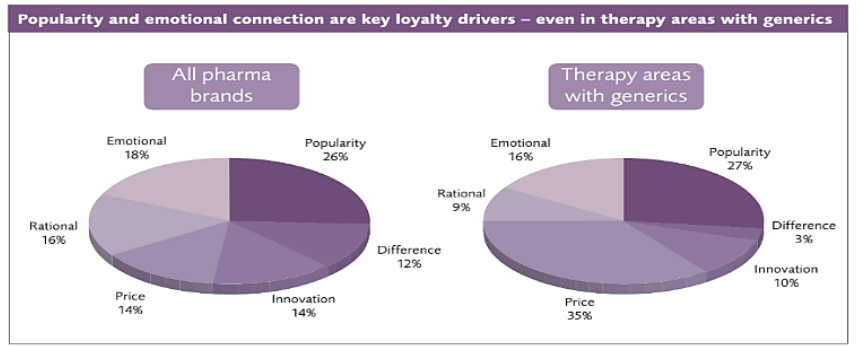

Source: A Practical guide by Trevor Acreman (10 ways to increase sales through stronger brand equity)

Fig. 4: Popularity and emotions drive brand loyalty

As shown in the Fig. 4, the Lipitor loyalist mostly values the rational benefits, Lipitor offers to them and their patients. For Crestor loyalist it's both the rational benefits and sense of innovation that keep them loyal. Neither Lipitor nor Crestors scores as well as they might like to in terms of their emotional connection- something both are addressing in their latest advertising campaigns.

In this context, following aspects are worth mentioning:

1. How to build emotional advantage, especially when there is little or no rational differentiation? This common question in the consumer world is beginning to be asked of pharmaceuticals brands now too.

2. Neuroscience and neuro-marketing suggest that there is one common currency of decision-making -"feeling good".

3. The strongest brands have the most lucidity and differentiation in terms of their positioning and vision. These brands also have a greater likelihood to grow share than less differentiated brands. This is no correlation. Brands are all about giving a shortcut to meaning and hence making decision making easier. Therefore, whatever it stand for, stand for something ideally something important! 
4. If the brand is therapy leading, show it and if not act like it! This way the content and the amount of marketing communication will focus it as a leader. The thumb rule to grow share is for effective share of marketing spend to exceed your market share. Leadership position will have future synergistic effect.

5. In building leadership and lucidity there should be consistency in marketing content and communication. Most of the campaigns have run for many years by various different creative executions. Also, make sure what is been used in detail aid, print advertising and make use of events and online. The rise in the internet source is increased in particular; hence, the world is getting smaller and smaller so think of the synergies across the border.

\section{Factors affecting Brand Equity}

Following factors have impact on brand equity:

1. Direct to Consumer (DTC) Advertising

2. The Role of (Marketing) Communications

\section{Direct-to-consumer (DTC) Advertising}

Direct-to-consumer (DTC) advertising can be a very effectual medium. However, it frequently neglects to get crosswise over what really matters to the brand. The main problem with DTC, in terms of the fact and information must be given legally so that the information is usually conditional information and is given in such a context that people do not really understand it fully. Hence, it becomes very difficult to have a balanced communication with the customer, and this limitation impacts on brand.

One of the main issues for DTC is the use of television. Television is a single-minded media; it is all about putting one view across. However, in a 30/60 second business it is exceptionally hard to get over various diverse ideas. While really what need to stated is "this works quicker", an entire host of extra qualifying data is incorporated to keep up "reasonable adjust" and the key message that are attempting to put crosswise over gets lost. It is vital to have an exceptionally straightforward message in DTC battles; otherwise, they are confusing and not cost effective means of communication.

For decades, prescription drugs manufacturer advertizes their product exclusively who were expected to interpret drug information. In the early 1990, some drug manufacturing started focusing on consumer due, to a limited extent, to the aging baby boomers and to an increase in the number of patients participating in their own health care decisions. Hence, DTC advertising has become more popular promotional tool.

The FDA manages the promotion of prescription drug products under Federal Food, Drug and cosmetic Act and related regulation. This implies the agency must guarantee that physician recommended tranquilize data gave by medication firms is honest, adjusted, and precisely conveyed and this expert through an exhaustive reconnaissance, authorization, and training program, and by cultivating better correspondence of naming and limited time data to both well-being experts and customers. The 500-doctor review, released in November 2004, is the third in a progression of assessments that the FDA is utilizing to see better how DTC professionally prescribed medication advancement influences the patient-specialist relationship. The survey done by physician and two previous consumer surveys indicate that awareness of DTC ads is increasing. For example, nearly $81 \%$ of consumer respondents in 2002 reported seeing or hearing an ad for a prescription drug. This value is up from $72 \%$ in 1999. But 58\% agreed strongly that DTC ads make the drugs seem better than they really are.

The results of all three surveys will help the agency decide whether advertising rules need to be changed to ensure better consumer understanding of a prescription drug's risks and benefits.

One of the unintended results or outcomes of direct-toconsumer (DTC) advertising and one-on-one marketing to physicians are that, interestingly, pharmaceutical brands are now "brands" in the same sense that major customer packaged goods brands, for example "Apple," "Crest," or "Shell" are brands. Demand for brands like "Lipitor" and "Viagra" has been created because there are meanings attached to these brands and emotional benefits upon which they are being marketed. They are not just trademarked pneumonic devices for a chemical entity.

Today's Landscape states that "These are most fascinating, but scary times for pharmaceuticals," said by Dr. Larry Friedman, Global Director, Brand and Advertising Research TNS, speaking at a recent Webinar hosted by PharmaVOICE and TNS Healthcare. "There is couple of new blockbusters on the horizon and numerous profitable drugs are coming off patent. Pharmaceutical organization has rare assets to deal with this situation and every function wants to be taken sternly when these assets are marshaled. Everybody needs a seat at the decision-making table.

A pharmaceutical marketer who wants to seat at the decision-making table, they must know how marketing can contribute to long-term company financial performance and the real value that marketers can provide over the years in future. Data and methodological limitations will not be accepted as an excuse, according to Friedman. The mandate is to dig deeper, think differently and come up with ideas for creating long-term value in the brand.

\section{Generics and Brand equity}

Pharmaceutical industries use various techniques and strategies to extend the life of brand name drugs beyond patent expiry. Often, drug companies having brand litigate aggressively to extend patent protection for their products and to keep generic versions off the market, a process referred to by some critics as "ever-greening."

These tactics are fine. Eventually, however, patent battles are lost, and drugs brand name often disappear.

"Real commitment, which includes both emotional and psychological attachment, has been developed for some Rx drug brands," says Friedman. A vital implication of this is that it is no longer acceptable to think of the value of a 
brand only extending as long as the original chemical's patent period. To do so is to leave huge amounts of cash on the table. It's critical for industries to create such important strategies that build brand value over time-and extend it beyond expiry.

In past expenses, could be recovered before the finish of the patent period. Today, the world is extremely distinctive. The expenses to create medications are higher furthermore; there is tremendous pressure on costs. A lot of cash is being spent on promoting and deals endeavors that go on while the brand is in-line, not quite recently at the acquaintance of the brand with the market. As a result, ventures may not be completely recovered by the finish of the patent period.

\begin{tabular}{|l|l|}
\hline Old model & New model \\
\hline $\begin{array}{l}\text { Spend at launch, little } \\
\text { afterwards }\end{array}$ & $\begin{array}{l}\text { Marketing/sales efforts } \\
\text { ongoing while in-line }\end{array}$ \\
\hline $\begin{array}{l}\text { Costs recouped by end } \\
\text { of patent period }\end{array}$ & $\begin{array}{l}\text { In-line investments not fully } \\
\text { recouped by end of patent } \\
\text { period }\end{array}$ \\
\hline $\begin{array}{l}\text { Brand value "used up" } \\
\text { at end of patent period }\end{array}$ & $\begin{array}{l}\text { Brand value built up over life } \\
\text { of patent }\end{array}$ \\
\hline
\end{tabular}

The brand value that is developed over time does not go to zero at the end of the patent time frame. Just consider real brands that are going off patent in the coming years and how much cash is being spent on advertising. Then, consider the strong consumer commitment that has been built up toward those brands. Clearly, companies do not want to lose that equity just because their brands are facing expiration. They need brand architecture models that will let them continue to leverage the commitment they've built over the long termeven after expiry.

There is a great deal of residual brand incentive at patent expiry left on the table. A few advertisers have understood this potential, in spite of the fact that they have not articulated it well nor have they thought deliberately about how to extend their brand image through better portfolio management or more successful brand design models.

A few organizations have found a way to address extending equity. For example, they have developed new structures, new signs or new conveyance frameworks. The market has seen an expanded in the quantity of product, as Ambien CR, which is intended to extend the life of a brand.

To gain a genuine upper hand, be that as it may, pharma organizations must think all the more deliberately about portfolio management and brand engineering. They should answer a variety of key questions to help them streamline the estimation of their brands:

1. When should be a new brand created- and when should an existing name continued to be used?

2. How should brands within the portfolio relate to each other?

3. How can brand family be strengthened?

4. Ultimately, how can overall corporate equity be reinforced?
"These are basic questions that many companies in other industries have been thinking about over many years but are actually fairly new within the pharmaceutical industry," says Friedman. "The industry should not trifle with these questions or abandon them to junior levels. Senior administration must stride up to the plate and think deliberately about how to structure and oversee brands and the value stream among them."

\section{Brand Architecture Model}

Brand design refers to how an organization structures its brands and how it deals with the stream of value between brands in its portfolio. "Choices around brand architecture are the absolute most essential choices that key senior level officials can make," says Friedman. "These choices have broad ramifications for completely catching the estimation of brands after some time."

There are a few diverse brand design models that an organization may consider. We should take a look at the "extremes" first. One extraordinary is the independent model in which brands are all "specialist brands" and the value of one brand has no effect on another. Under this display, you wouldn't realize that more than one brand is made by a similar organization. Every brand is truly independent of the each other.

For example, $P \& G$ has number of extraordinary healthcare brands, including Actonel, Crest, Macrobid, Metamucil, Nyquil/Dayquil, PeptoBismol, Scope, and Vicks. There is no P\&G brand. There is no flow of equity between brands. All the equity stays within each individual brand. The other "extraordinary" is the masterbrand model in which equity for all items in the portfolio accumulate to one general brand. There are no sub-brands. GE is a decent case of a masterbrand. There are GE Appliances, GE Aircraft Engines, etc.

\section{Combination Drugs}

Over the past few years, there is been seen increasing numbers of combination drugs introduced into the market under new brand names. For example, Vytorin, is a newly named drug that is a combination of two established brands (Zetia and Zocor). Two or more drugs which are combined to create a new brand have not always been a successful strategy. In fact, in some cases, market results may have been better if a shared brand was employed.

\section{Understanding Equity Flow}

Statistical surveying has a role in understanding equity flow. Survey research data can be an essential part to make choices on the most proficient method to shape a mark design or restore brand architecture for an organization. Through multivariate analysis of characteristic information gathered throughout statistical surveying overviews (e.g., BPO, SPO - TNS Branded Solutions) which can factually decide how equities can flow out of Master brands to subbrands, the other way around, and among sub-brands," says Freidman. 
We can look at how sub-brands are associated due to the property qualities they have. As shown in Fig. 5, the master brand and item in classification \#1 share the properties "mark claims essentially to masters" and "are on most models." So by concentrating on those characteristics for that sub-mark in that item class, value will stream back to the masterbrand and help reinforce it.

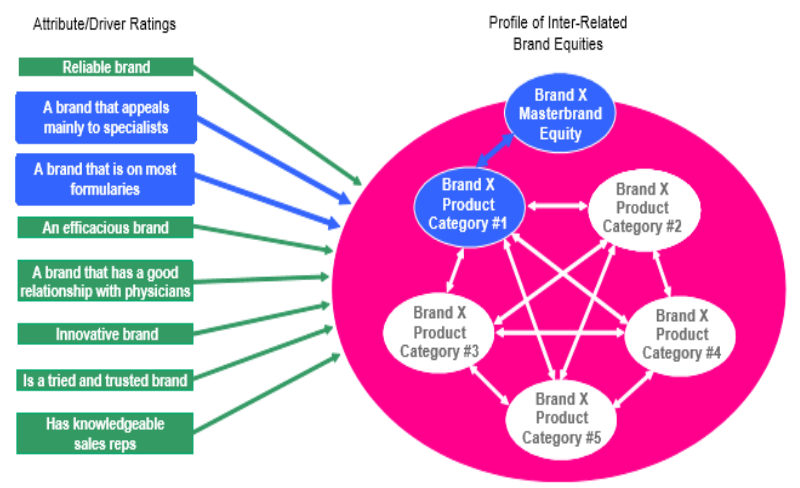

Fig. 5: Inter-related brand equities

To summarize, we can say that brand equity models are changing and are customer-centric in nature. They take into account relationship between the brand and the end user (consumer). Some of these aspects are brand characteristics (salience), brand performance and brand imagery, consumer perception in terms of the judgement and feelings (towards the brand) and association of brand and the consumer (resonance) (Fig. 6).

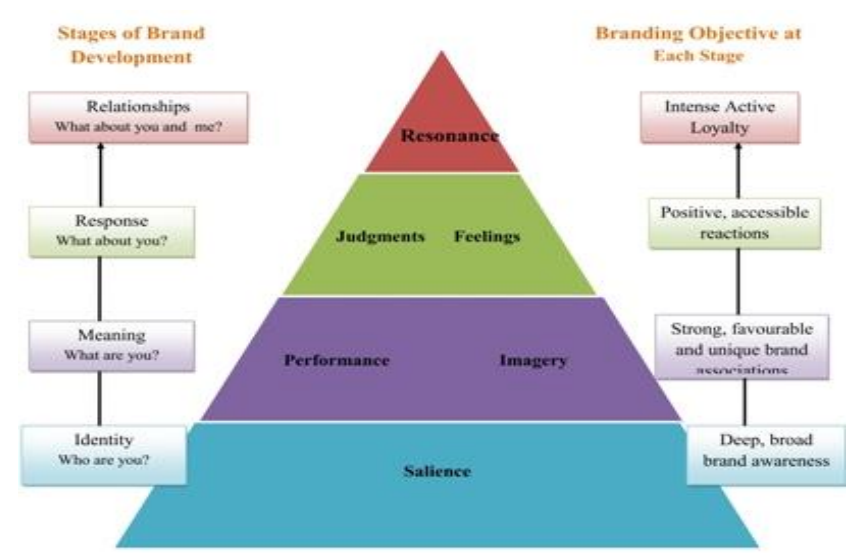

Fig. 6: Brand equity model based on consumer needs (SimplyNotes)

\section{The Role of (Marketing) Communications}

"To use an expression, blockbusters, are like rich people. They are not like you or I, they're different," quips Ian McKinnon, Ph.D., Senior Vice President, Advanced Methods, TNS Healthcare. "They can make or break a company. The challenge is to identify these brands early, create a success plan for them, and monitor that plan over time."
"Communications Management starts long before launch," says McKinnon, "As its primary purpose, it must place and maintain the brand on its trajectory toward becoming a blockbuster. Secondarily, it must enable the blockbuster's equity to flow back to the portfolio or to the manufacturer."

McKinnon cites 5 steps to realizing the potential of a blockbuster brand:

1. Identifying a Brand's Potential

2. Identifying How to Capture a Brand's Potential

3. Executing a Brand's Success Plan

4. Monitoring and Managing the Success Plan

5. Retaining Brand Equity during Maturity and Patent Expiration.

The first three steps may be used during pre-launch stage and the last two steps may be used during post-launch stage.

\section{Conclusion}

This article concludes that there are not only ways to determine the brand equity but there are various factors that are to be considered while making these changes in various brands. The various methods of brand equity used by Pfizer are one of the most effective methods that are used. These involve the increase in the sales force and also creating awareness programmes. Apart from these there are other factors such as brand awareness, brand loyalty etc which is also considered to increase the brand equity such as the generics in the market, as the increase in the generics these are the threats that are possessing to the pharma companies. Thus various methods are used are the internal and the external methods. Thus one should always consider all these factors when building brand equity as well as building a brand image in the eyes of the consumers as well as the brand loyal customers. These not only will help to increase the brand loyalty among the customers but also the help to sustain the market position in the market.

\section{Source of Funding}

None.

\section{Conflict of Interest}

None.

\section{References}

1. Blackeett Tom. (2005). Branding in the pharmaceutical industry. Packing packaging.

2. Gaurav K, Benita E. Storm ahead: Can big pharma be saved? Brandweek, 2004:45:28-9.

3. Lane KK. (2005). Strategic Brand Management: building, Measuring and Managing Brand Equity. Pearson Education International, New Jersey.

4. Patricia M. Building and emotional connection: A five step branding process. Medical Marketing and Media, 2004;39(5):52.

5. Panchal SK, Khan BM, Ramesh S. (2012). Importance of 'brand loyalty, brand awareness and perceived quality parameters' in building brand equity in the Indian pharmaceutical industry. J Med Marketing. 2012;12(2):81-92. 
6. Isabele S, Giles M. (2004a). How different are branding strategies for pharmaceutical industry and the fast moving consumer goods sector? J Brand Manag. 2004a:11(5):36.

7. Isabele $\mathrm{S}$, Giles M. A brand logic for pharma?: A possible strategy based on FMCG experience. Int J Med Marketing. 2004b;4(1):55.

\section{Website}

https://www.ama.org/publications/eNewsletters/MHSNewsletter/Pages /study-quantifies-most-valuable-pharma-brands.aspx

http://www.marketstrategies.com/user_area/content_media/OBR_09_J un.pdf

https://www.rankingthebrands.com/The-Brand-

Rankings.aspx? rankingID $=370$
http://www.fda.gov/Drugs/ResourcesForYou/Consumers/ucm143562.h tm.

https://www.drugwatch.com/2012/01/18/direct-to-consumermarketing.

http://www.simplynotes.in/mbabba/brand-resonance-pyramidstagesof-brand-development/

How to cite this article: Panigrahi A, Joshi V. Developing brand equity through consumers: A study of pharmaceutical industry. J ManagRes Anal. 2020;7(4):159-66. 